\title{
Recommendations for assessing Patient-Reported Outcomes and Health-Related quality of life in clinical trials on allergy: a GA ${ }^{2}$ LEN taskforce position paper
}

\author{
I. Baiardini ${ }^{1}$, P. J. Bousquet ${ }^{2}$, Z. Brzoza ${ }^{3}$, G. W. Canonica ${ }^{1}$, E. Compalati ${ }^{1}$, A. Fiocchi ${ }^{4}$, W. Fokkens ${ }^{5}$, \\ R. G. van Wijk ${ }^{6}$, S. La Grutta ${ }^{7}$, C. Lombardi ${ }^{8}$, M. Maurer ${ }^{9}$, A. M. Pinto ${ }^{10}$, E. Ridolo ${ }^{11}$, \\ G. E. Senna ${ }^{12}$, I. Terreehorst ${ }^{5}$, A. Todo Bom ${ }^{13}$, J. Bousquet $^{14}$, T. Zuberbier $^{9}$ \& F. Braido ${ }^{1}$ \\ ${ }^{1}$ Allergy \& Respiratory Disease Clinic, Ospedale S.Martino Genova, Genova, Italy; ${ }^{2}$ University hospital, Department of Biostatistics, Nimes, \\ France; BESPIM; ${ }^{3}$ Department of Internal Diseases, Allergology and Clinical Immunology, Medical University of Silesia, Katowice, Poland; \\ ${ }^{4}$ Department of Child and Maternal Medicine, The Melloni University Hospital, Milan, Italy; ${ }^{5}$ Department of Otorhinolaryngology, Academic \\ Medical Center, Amsterdam, the Netherlands; ${ }^{6}$ Erasmus Medical Center in Rotterdam, the Netherlands; ${ }^{7}$ Environment and Health Unit, \\ ARPA Sicilia and Institute of Biomedicine and Molecular Immunology (IBIM), Italian National Research Council (CNR), Palermo, Italy; \\ ${ }^{8}$ Pneumoallergology Unit, S. Orsola FBF Hospital, Brescia, Italy; ${ }^{9}$ Department of Dermatology and Allergy, Allergie-Centrum-Charite/ECARF, \\ Charité- Universitätsmedizin Berlin, Germany; ${ }^{10}$ Faculty of Medicine, Institute of Pathophysiology, Coimbra University, Coimbra, Portugal; \\ ${ }^{11}$ Clinical Sciences, University of Parma, Parma, Italy; ${ }^{12}$ Allergy Service, Verona Major Hospital, Verona, Italy; ${ }^{13}$ Department of Immuno \\ Allergology, Coimbra University Hospital, Coimbra, Portugal; ${ }^{14}$ Department of Respiratory Medicine, Montpellier University and INSERM \\ U780, Montpellier, France
}

To cite this article: Baiardini I, Bousquet PJ, Brzoza Z, Canonica GW, Compalati E, Fiocchi A, Fokkens W, van Wijk RG, La Grutta S, Lombardi C, Maurer M, Pinto AM, Ridolo E, Senna GE, Terreehorst I, Todo Bom A, Bousquet J, Zuberbier T, Braido F. Recommendations for assessing Patient-Reported Outcomes and HealthRelated quality of life in clinical trials on allergy: a GA²LEN taskforce position paper. Allergy 2010; 65: $290-295$.

\section{Keywords}

health-related quality of life; patient-reported outcomes.

\section{Correspondence \\ Ilaria Baiardini, Allergy \& Respiratory \\ Disease Clinic, Ospedale S.Martino, Pad. \\ Maragliano, Largo Rosanna Benzi 10, 16132 \\ Genova, Italy.}

Accepted for publication 9 October 2009

DOI:10.1111/j.1398-9995.2009.02263.x

Edited by: Marek Kowalski

\begin{abstract}
The aim of this Global Allergy and Asthma European Network (GA ${ }^{2}$ LEN) consensus report is to provide recommendations for patient-reported outcomes (PROs) evaluation in clinical trials for allergic diseases, which constitute a global health problem in terms of physical, psychological economic and social impact. During the last 40 years, PROs have gained large consideration and use in the scientific community, to gain a better understanding of patients' subjective assessment with respect to elements concerning their health condition. They include all health-related reports coming from the patient, without involvement or interpretation by physician or others. PROs assessment should be performed by validated tools (disease-specific tools when available or generic ones) selected taking into account the aim of the study, the expected intervention effects and the determinant and confounding factors or patient-related factors which could influence PROs. Moreover, each tool should be used exclusively in the patient population following the authors' indications without modification and performing a cross-cultural validation if the tool must be used in a language that differs from the original. The result analysis also suggests that the relevance of PROs results in any interventional study should include a pre-post assessment providing information concerning statistical differences within or among groups, rates of response for the PROs and a minimal important difference for the population. The report underlines the importance of further investigation on some topics, such as the quality assessment of existing PROs tools, the definition of inclusion and exclusion criteria and a more extensive evaluation of the correlation between PROs, besides health-related quality of life, and clinical data.
\end{abstract}

\footnotetext{
Abbreviations

EMEA, European Medicines Agency; FDA, United States (US) Food and Drug Administration; HRLQ/HRQoL, health-related quality of life; MID, minimal important difference; PROs, patient-reported outcomes.
} 


\section{Concept and definition of health-related quality of life (HRQoL or HRQL) and patient-reported outcomes (PROs)}

During the last 40 years, clinicians and researchers have recognized the importance of considering the subjective dimension of diseases to have a more global and coherent vision about the patient and the effects of the whole health-care process. This development was driven by the clinical necessity to go beyond the limits of 'disease-centred medicine' and reaches the wider and more global perspective of 'patient-centred medicine'. As mentioned in the WHO Health Report (2008): 'people-centredness is not a luxury, it is a necessity' (1). People do not think about health only in terms of targets for disease control programmes, but also in terms of what they perceive, according to their beliefs and their particular situation in life.

There are several definitions of this impact on subjective experience. Some researchers are prone to emphasize health aspects (HRQL or HRQoL); however, nowadays, the expression PROs seems to be more used, because it focuses on the interest in the whole host of outcomes. Anyway, it cannot be forgotten that in a nonclinical setting, PROs could mean Person-Reported Outcomes (2). PROs include all health-related reports coming from the patient, without involvement or interpretation by physician or others, such as symptoms, $H R Q L$, illness perception, satisfaction or adherence to treatment (3). Health Outcome Assessment has also been proposed to avoid specifying the respondent (1).

Patient-reported outcomes have recently gained large consideration and use in the scientific community, with the aim of gaining a better understanding of patient's subjective assessment with respect to elements concerning their health condition (4). PROs focus the attention only on the patient, because she or he is the only person authorized to provide information about the personal experience of the disease, treatment and care. Therefore, PROs provide information unavailable from other sources, such as laboratory measures, caregiver reports or physician's judgements that is crucial for predicting health outcomes and for establishing health policy.

Patient-reported outcomes must be evaluated by validated tools exploring the patients' perceptions related to outcome. Specifically developed instruments such as questionnaires, composite scores and visual analogue scale (VAS) are necessary to understand how the patients perceive and evaluate their disease experience and therapy effects (4).

Patient-reported outcomes are affected by disease-related aspects (e.g. severity, chronicity, treatment schedule) and patient-related factors (e.g. alexithymia, stress, coping, mood). Moreover, each PRO can be influenced by other PROs - e.g. the level of asthma control may influence the HRQoL (5).

Patient-reported outcomes evaluation is relevant in clinical, research, routine medical practice and regulatory processes. The United States (US) Food and Drug Administration (FDA) (6) and the European Medicines Agency (EMEA) (7) have recently focused on PROs evaluation. EMEA suggests that especially in nonlife-threatening chronic conditions, when two drugs show similar efficacy, the patient's evaluation provided by PROs could be useful in defining the drug to be recommended. Between 1999 and 2003, 34\% of all evaluations submitted to EMEA for the registration of a new drug, also for the use in the paediatric age (8), included data on HRQL and other PROs, and this rate has been constantly increasing ever since (9).

Recently, Scoggins and Patrick (10) showed that $14 \%$ of all international trials registered between September 2004 and September 2007 included a PRO as an outcome.

\section{PROs in allergic diseases}

Allergic diseases constitute a global health problem: they appear to be increasing in prevalence and account for significant morbidity and socioeconomic costs (11). On the basis of this evidence, they have been defined as one of the epidemics of the 21 st century (12).

Health-related quality of life impairment has been well established for rhinitis, asthma (13), atopic dermatitis (14), urticaria (15) and food (16). Allergic diseases exert a considerable economic and social impact not only because they are highly prevalent in many parts of world but also because their presence interferes significantly with many aspects of daily life as a result of physical discomfort and impairment along with emotional distress $(17,18)$.

A growing number of clinical trials for allergic diseases include PROs assessment (19-25). The aim of this GA ${ }^{2}$ LEN consensus report is to provide recommendations for PROs evaluation in clinical trials for allergic diseases.

\section{PROs as primary, co-primary or secondary outcome}

Assessment of PROs is rarely the primary but rather a secondary outcome in clinical trials (26-28). In this case, the trials sample size is calculated based on the primary outcome, and the results for PROs as a secondary outcome should be carefully evaluated in terms of the relationship between the PROs and the sample size.

The development of clinical trials in which PROs are the primary or co-primary (29) outcome is recommended because appropriate tools are available.

\section{Selection of instruments for PROs assessment}

- The assessment of PROs should be performed by validated tools selected according to the aim of the study.

- In clinical trials, disease-specific tools (whenever available) should be preferred over generic tools. Specific questionnaires are more sensitive than generic ones when measuring changes in the same population before and after an intervention. When a specific tool is not available, its development is recommended. A PROs tool can be considered validated if the validation procedure has been followed (Appendix S1), and if this procedure and its results are published in a peer-reviewed journal.

- However, because allergic disease can affect more than one organ simultaneously, some tools can be used for the assessment of different clinical features (30). 
- For HRQoL assessment, 'generic questionnaires' should be used when a specific tool is not available or for a comparison between two different populations of patients [e.g. rhinitis $v s$ asthma patients (13)] or between patients and healthy subjects (31). In this case, 'diseaseor symptom-specific questionnaires' may be used in association with generic tools or alone (32).

- In trials that assess specific effects of an intervention (e.g. effect on sleep, on pain...), the choice of a specific PROs tool, whenever available, should be made taking into account the expected intervention effects.

- When PROs evaluation is part of a trial, determinant and confounding factors influencing PROs should be considered.

- A Ga ${ }^{2}$ len registry of the validated tools is available on its Web site (http://www.ga2len.net). In the registry, the researchers can find data useful for the choice of the suitable tool according to the aim of the study (Table 1).

- All PROs and patient-related factors influencing PROs should be assessed using validated tools if available (Appendix S2).

- If symptoms are assessed using symptom scores, information about the validity, reliability and responsiveness of the tool should be provided when available (33).

- The VAS is a technique used to measure subjective phenomena (34). It is considered a robust, sensitive and reproducible method for symptom assessment (35). However, the interaction between the behavioural tendencies of patients and the physical characteristics of the scale causes it to be nonlinear and prone to response bias (3538). For this reason, an assessment is subjective, and these scales are more valuable when looking at changes within individuals and are less interesting for comparing across a group of individuals at 1 time point $(15,34,38)$.

Table 1 Health-related quality of life and patient-reported outcomes $\mathrm{Ga}^{2}$ len registry

Name of the tool

Acronym

Author

Bibliographic references of the original questionnaire

Target

Population

Administration

Original language

Existing translations

Numbers of items

Tool dimensions

Scaling of items

Scoring of items

List of items

Minimal important difference

Shortened versions

Performed trials

Copyright

Contact information
- The use of composite-validated clinical assessment tools e.g. Asthma Control Test (39) and Asthma Control Questionnaire (40) is useful in clinical trials and real life assessment. The development of such kind of tools in all allergic disorders is encouraged. However, tools that include clinical/functional measures (e.g. peak expiratory flow) beside PROs (e.g. symptoms) are not fully patient centred (41).

- The administration time of an instrument in a clinical trial should take into consideration the time frame it refers to (e.g. instruments that take into consideration what happened in the last 4 weeks are not suitable for short-term trials).

- The methods of trials should include the reason(s) for choosing the PROs instrument selected.

\section{Patient-reported bias}

In open-labelled trials, patient-reporting bias is troublesome, because the most obvious setting in which bias may be introduced by the patient is self-reported assessment, which represents the basis of PROs. Many examples can be listed such as pain scales and quality of life (42). Some of the most plausible factors inducing biases are apprehension bias (e.g. increased blood pressure when the subject is apprehensive), obsequiousness bias (subjects may want to please investigator) and expectation bias (43).

\section{Sample size and population in PROs assessment}

- At present, information on the minimal number of patients to be involved in a clinical trial is not available for each PROs tool. A power calculation should be based on tools' features and the estimation of the drop-out rate.

- Each tool is to be used exclusively in the patient population for which it was developed and validated (e.g. use of adults' tools in adolescents is not correct).

\section{Correct administration of tools}

- The use of PROs tools should follow the authors' indications (e.g. no medical or caregiver filling-in, no phone interview, no mail delivery if not indicated).

- The tool cannot be modified (items, instructions and response items), and no item can be added or removed.

- When using a tool, it should be checked whether its use is regulated or limited by patent copyright or commercial fees.

- A PROs tool can only be used in a language that differs from the original after translation and back-translation, and a cross-cultural validation is performed (Appendix S3). A simple translation of the tool is not sufficient.

\section{PROs result analysis}

- The used tool should be analysed according to its structure (e.g. factor scores, global score). The analysis 
of isolated items or item combinations different from the factors defined in the validation process is not allowed.

- Each score must be calculated according to authors' instructions.

- Complete results (i.e. positive) scores must be reported. The negative, no change and the number of missing data and response rates should be provided.

- It is not allowed to extend the results from one population to other patients populations (e.g. different age group/demographical data, disease severity, duration of treatment, etc.).

- Patient-reported outcomes analyses and reporting in clinical trials should take into account and/or be adjusted for confounding/influencing factors. These factors should be declared in advance.

- The relevance of PROs results in any interventional study should include a pre-post assessment. The results should provide information concerning statistical differences within groups or among groups, rates of response for the PROs outcome and a minimal important difference (MID) (44) for the population. This is relevant, because a single MID value for a PRO instrument does not exist across all patient samples. The MID may be different according to population and context, and no single MID may be valid for all study applications which refer to a PROs tool (45). Because the sample size of the study can be calculated only through study power, type I error and the expected effects, and these elements can be assumed only by past experiences, the use of MID calculated on previous studies is recommended.

\section{Unexplored areas and suggested topics of investigation}

- Existing tool should undergo widespread cross-cultural validation to allow for their use in large multicentre international trials. New tools that are developed should be simultaneously validated in different languages (46).

- Minimal important differences for specific populations and PROs tools should be established.

- Further quality assessment of existing PROs tools is needed.
- The development of clinical trials in which PROs are the primary outcome is recommended.

- The correlation among PROs, patient factors influencing PROs as well as the correlation among PROs themselves should be explored.

- The impact of doctor/patient communication on PROs needs investigations, because currently patients' and doctors' viewpoints on the quality of their relationship differ significantly (47).

- Instruments for symptoms assessment should be optimized through a validation process.

- Patients influencing PROs should be investigated as factors to be taken into account in inclusion and exclusion criteria definition.

- A more extensive evaluation of the correlation between PROs, besides HRQoL, and clinical data is needed.

- For the paediatric population, the extensive use of PROs and the development in the paediatric investigation plans (PIPs) should be strongly encouraged. PIPs were introduced by the European Commission to help ensure that medicines for children are included in the mainstream drug development process in Europe, rather than as an optional extra (48).

\section{Acknowledgment}

Authors acknowledge Dr Marianna Bruzzone for linguistic revision.

\section{Supporting Information}

Additional Supporting Information may be found in the online version of this article:

Appendix S1. Steps for PROs instrument validation.

Appendix S2. Examples of Patient-Reported Outcome (PRO) instruments and examples of Patient-Related Factors that influence PROs.

Appendix S3. Cross-cultural validation.

Glossary.

Please note: Wiley-Blackwell are not responsible for the content or functionality of any supporting materials supplied by the authors. Any queries (other than missing material) should be directed to the corresponding author for the article.

\section{References}

1. The World Health Report 2008. Primary health care - now more than ever. Geneva: World Health Organization, 2008.

2. Fayers P, Machin D. Quality of life. The assessment, analysis and interpretation of patient-reported outcomes, 2nd edn. Hoboken, NJ: John Wiley \& sons, 2007.

3. Patrick DL, Burke LB, Powers JH, Scott JA, Rock EP, Dawisha S et al. Patientreported outcomes to support medical product labeling claims: FDA perspective.
Value Health 2007;10(Suppl. 2):

S125-S137.

4. Rothman ML, Beltran P, Cappelleri JC, Lipscomb J, Teschendorf B, Mayo/FDA Patient-Reported Outcomes Consensus Meeting Group. Patient-reported outcomes: conceptual issues. Value Health 2007;10 (Suppl. 2):S66-S75.

5. Braido F, Baiardini I, Balestracci S, Ghiglione V, Stagi E, Ridolo E et al. Does asthma control correlate with quality of life related to upper and lower airways? A real life study. Allergy 2009;64:937-943.

6. US Department of Health and Human Services FDA Center for Drug Evaluation and Research, US Department of Health and Human Services FDA Center for Biologics Evaluation and Research and US Department of Health and Human Services FDA Center for Devices and Radiological Health. Guidance for Industry: patient reported outcome measures: use in medical product 
development to support labelling claims: draft guidance. Health Qual Life Outcomes 2006; 4:79.

7. European Medicines Agency. Committee for medicinal products for human use (CHMP). Reflection paper on the regulatory guidance for the use of health-related quality of life (HRQoL) measures in the evaluation of medicinal products. 2005. European Medicines Agency website. Available at: http:// www.emea.europa.eu/pdfs/human/ewp/ 13939104en.pdf. Accessed June 2009.

8. Regulation (EC) No 1901/2006 of the European Parliament and of the Council on medicinal products for paediatric use, amended by Regulation (EC) No 1902/2006.

9. Szende A, Leidy NK, Revicki D. Healthrelated quality of life and other patientreported outcomes in the European centralized drug regulatory process: a review of guidance documents and performed authorizations of medicinal products 1995 to 2003. Value Health 2005;8:534-548.

10. Scoggings JF, Patrick DL. The use of patient-reported outcomes instruments in registered clinical trials: evidence from ClinicalTrials.gov. Contemp Clin Trials 2009;30:289-292.

11. Bousquet J, Khaltaev N. Global surveillance, prevention and control of Chronic Respiratory Diseases. A comprehensive approach. Global Alliance against Chronic Respiratory Diseases. Geneva: World Health Organization. ISBN 9789241563468 , 2007:148 pp.

12. Asher MI, Montefort S, Björkstén B, Lai CK, Strachan DP, Weiland SK et al. Worldwide time trends in the prevalence of symptoms of asthma, allergic rhinoconjunctivitis, and eczema in childhood: ISAAC phases one and three repeat multicountry crosssectional surveys. Lancet 2006;368:733-743.

13. Leynaert B, Neukirch C, Liard R, Bousquet J, Neukirch F. Quality of life in allergic rhinitis and asthma. A population-based study of young adults. Am J Respir Crit Care Med 2000;1:1391-1396.

14. Lewis-Jones S. Quality of life and childhood atopic dermatitis: the misery of living with childhood eczema. Int $J$ Clin Pract 2006;60:984-992.

15. Maurer M, Ortonne JP, Zuberbier T. Chronic urticaria: a patient survey on quality-of-life, treatment usage and doctorpatient relation. Allergy 2009;64:581-588.

16. Flokstra-de Blok BM, Dubois AE. Quality of life in food allergy: valid scales for children and adults. Curr Opin Allergy Clin Immunol 2009;9:214-221.

17. Gerth van Wijk R. Allergy: a global problem. Quality of life. Allergy 2002;57:1097-1110.

18. Baiardini I, Braido F, Brandi S, Canonica $\mathrm{GW}$. Allergic diseases and their impact on quality of life. Ann Allergy Asthma Immunol 2006;97:419-428.

19. Mancuso CA, Rincon M, McCulloch CE, Charlson ME. Self-efficacy, depressive symptoms, and patients' expectations predict outcomes in asthma. Med Care 2001;39:13261338.

20. Georgiou A, Pearson M. Measuring outcomes with tools of proven feasibility and utility: the example of a patient-focused asthma measure. $J$ Eval Clin Pract 2002;8:199-204.

21. Oga T, Nishimura K, Tsukino M, Sato S, Hajiro T, Koyama $\mathrm{H}$ et al. Longitudinal changes in patient vs. physician-based outcome measures did not significantly correlate in asthma. J Clin Epidemiol 2005;58:532539.

22. Jenkins CR, Thompson PJ, Gibson PG, Wood-Baker R. Distinguishing asthma and chronic obstructive pulmonary disease: why, why not and how? Med J Aust 2005;1:S35S37.

23. Haughney J, Cotton P, Rosen JP, Morrison $\mathrm{K}$, Price D. The use of a modification of the Patient Enablement Instrument in asthma. Prim Care Respir J 2007;16:89-92.

24. Fox P, Porter PG, Lob SH, Boer JH, Rocha DA, Adelson JW. Improving asthma-related health outcomes among low-income, multiethnic, school-aged children: results of a demonstration project that combined continuous quality improvement and community health worker strategies. Pediatrics 2007;120:e902-e911.

25. Thomas M, Sheran J, Smith N, Fonseca S, Lee AJ. AKL1, a botanical mixture for the treatment of asthma: a randomised, doubleblind, placebo-controlled, cross-over study. BMC Pulm Med 2007;7:4.

26. Baiardini I, Braido F, Tarantini F, Porcu A, Bonini S, Bousquet PJ et al. ARIA-suggested drugs for allergic rhinitis: what impact on quality of life? A GA2LEN review. GA2LEN Allergy 2008;63:660-669.

27. Baiardini I, Braido F, Brandi S, Tarantini F, Bonini S, Bousquet PJ et al. The impact of GINA suggested drugs for the treatment of asthma on Health-Related Quality of Life: a GA(2)LEN review. Allergy 2008;63:1015-1030.

28. Grob JJ, Gaudy-Marqueste C. Urticaria and quality of life. Clin Rev Allergy Immunol 2006;30:47-51.

29. Bachert C, Bousquet J, Canonica GW, Durham SR, Klimek L, Mullol J et al. Levocetirizine improves quality of life and reduces costs in long-term management of persistent allergic rhinitis. J Allergy Clin Immunol 2004;114:838-844.

30. Baiardini I, Pasquali M, Giardini A, Specchia C, Passalacqua G, Venturi S et al. Rhinasthma: a new specific QoL questionnaire for patients with rhinitis and asthma. Allergy 2003;58:289-294.

31. Bousquet J, Bullinger M, Fayol C, Marquis P, Valentin B, Burtin B. Assessment of quality of life in patients with perennial allergic rhinitis with the French version of the SF-36 Health Status Questionnaire. J Allergy Clin Immunol 1994;1:182-188.

32. van Oene CM, van Reij EJ, Sprangers MA, Fokkens WJ. Quality-assessment of diseasespecific quality of life questionnaires for rhinitis and rhinosinusitis: a systematic review. Allergy 2007;62:1359-1371.

33. Wasserfallen JB, Gold K, Schulman KA, Baraniuk JN. Development and validation of a rhinoconjunctivitis and asthma symptom score for use as an outcome measure in clinical trials. J Allergy Clin Immunol 1997;100:16-22.

34. Wewers ME, Lowe NK. A critical review of visual analogue scales in the measurement of clinical phenomena. Res Nurs Health 1990;13:227-236.

35. Langley GB, Sheppeard H. The visual analogue scale: its use in pain measurement. Rheumatol Int 1985;5:145-148.

36. Bousquet PJ, Combescure C, Klossek JM, Daurès JP, Bousquet J. Change in visual analog scale score in a pragmatic randomized cluster trial of allergic rhinitis. J Allergy Clin Immunol 2009;123:1349-1354.

37. Williamson A, Hoggart B. Pain: a review of three commonly used pain rating scales. J Clin Nurs 2005;14:798-804.

38. Turner D, Schünemann HJ, Griffith LE, Beaton DE, Griffiths AM, Critch JN et al. Using the entire cohort in the receiver operating characteristic analysis maximizes precision of the minimal important difference. J Clin Epidemiol 2009;62:374-379.

39. Nathan RA, Sorkness CA, Kosinski M et al. Development of the asthma control test: a survey for assessing asthma control. J Allergy Clin Immunol 2004;113:59-65.

40. Juniper EF, O'Byrne PM, Guyatt GH, Ferrie PJ, King DR. Development and validation of a questionnaire to measure asthma control. Eur Respir J 1999;14:902-907.

41. Steven K, Neville RG, Hoskins G, Sullivan FM, Drummond N, Alder EM. The RCP's 'Three Key Questions' for asthma: review of practical use. Br J Community Nurs 2002;7:300-303.

42. Day S. Open-labelled trials. In: D'Agostino R, Sullivan L, Massaro J, editors. Wiley Encyclopedia of Clinical Trials. Hoboken, NJ: John Wiley \& sons, 2008:304-309.

43. Sackett D. Bias in analytic research. J Chronic Dis 1979;32:51-63.

44. Guyatt GH, Osoba D, Wu AW, Wyrwich KW, Norman GR. Clinical Significance Consensus Meeting G. Methods to explain the clinical significance of health status 
measures. Mayo Clin Proc 2002;77: 371-383.

45. Revicki D, Hays RD, Cella D, Sloan J. Recommended methods for determining responsiveness and minimally important differences for patient-reported outcomes. $J$ Clin Epidemiol 2008;61:102-109.

46. Hunt SM, Alonso J, Bucquet D, Niero M, Wiklund I, McKenna S. Cross-cultural adaptation of health measures. European Group for Health Management and Quality of Life Assessment. Health Policy 1991;19:33-44.

47. Maurer M, Zuberbier T. Undertreatment of Rhinitis Symptoms in Europe: findings from a cross-sectional questionnaire survey. Allergy 2007;62:1057-1063.
48. Communication from the Commission. Guideline on the format and content of applications for agreement or modification of a paediatric investigation plan and requests for waivers or deferrals and concerning the operation of the compliance check and on criteria for assessing significant studies. Official Journal C 2008;243:1-12. 